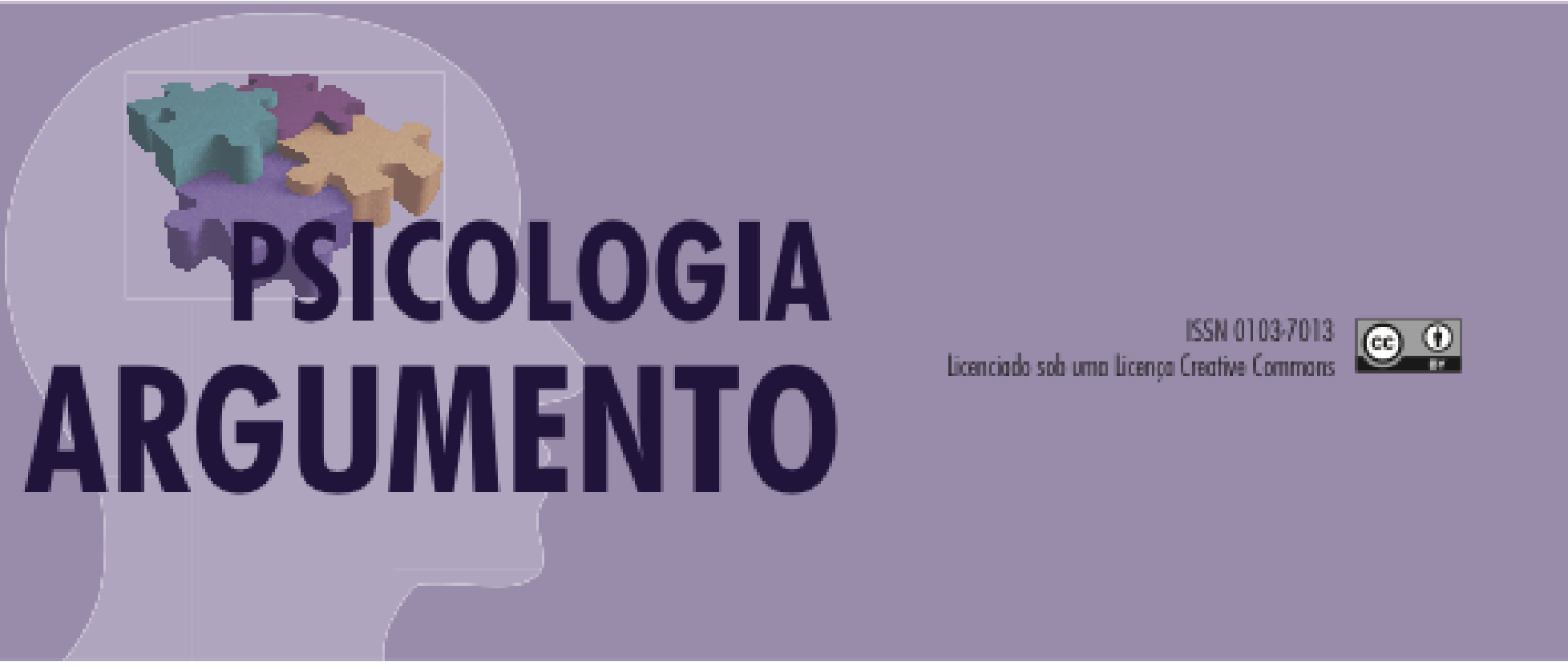

doi $10.7213 /$ psicol.argum.33.082.A007

\title{
Filhos nascidos no cárcere e as dificuldades do exercício da maternidade em ambiente prisional
}

\author{
Children born in prison and the difficulties of motherhood in \\ prison environment
}

\section{Gabriela Reyes Ormeño [a], Ana Carina Stelko-Pereira [b]}

[a] Dra. em Psicologia, Professora Adjunta do Mestrado em Psicologia Forense da Universidade Tuiuti do Paraná. Curitiba Paraná - gabriela.reyes@utp.br

[b] Dra. em Psicologia, Professora Adjunta do Programa de Pós-graduação em Saúde Coletiva da Universidade

Estadual do Ceará. Fortaleza- Ceará, Coordenação de Psicologia. Email: anastelko@gmail.com

\section{Resumo}

Poucos são os estudos sobre mulheres encarceradas e seus bebês no Brasil. Este estudo investigou a percepção da mãe encarcerada sobre os aspectos relevantes do ambiente prisional relativos ao desenvolvimento do bebê neste recinto. Participaram deste estudo três mães encarceradas cujos filhos estavam ou haviam ficado sobre seus cuidados enquanto cumpriam pena, as quais tinham cerca de 23 anos e cumpriam condenação por tráfico de drogas em um Centro de Regime Semi- Aberto. Utilizou-se como instrumento da pesquisa uma entrevista semi- estruturada a qual investigava informações sóciodemográficas, concepção de maternidade e como eram os cuidados e as preocupações com o bebê no cárcere, tendo como duração aproximada de duas horas. O método empregado foi estudo de casos coletivos e fez-se uma análise de conteúdo das informações. Enquanto resultados, observou-se que todas as participantes tinham uma relação positiva de vínculo mãe-bebê, acreditando na importância do cuidado materno como essencial. Contudo, apontaram que as normas restritivas do presídio causavam prejuízo ao desenvolvimento infantil, de modo que preferiam que algum familiar passasse a cuidar do bebê ainda que este fosse a única fonte de afeto que tinham no ambiente prisional. Seria importante que estudos futuros incluíssem um número maior de casos e outros informantes. Conclui-se serem necessárias adaptações no 
sistema penitenciário de modo a atender as necessidades dos filhos de encarceradas que residem no presídio e sugere-se a promoção do vínculo mãe-bebê como uma maneira de facilitar a ressocialização da encarcerada.

Palavras-chave: prisões, mães encarceradas, primeira infância

\begin{abstract}
There are few studies about incarcerated mothers and their babies in Brazil. This study investigated the relevant aspects of prison environment to babies under incarcerated mother's perspectives. Participated on the study three incarcerated mothers whose children were or have been on their care during incarceration that had an average age of 23.3 years and were convicted of drug trafficking at the Center for Semi-Open Female Board. An approximately two hour long semi-structured interview was applied as research instrument, including questions about the sociodemographic information of incarcerated, conception of motherhood, how they took care of the baby and the concerns with the baby living in prison environment. For the method, it was analyzed the compliance of case studies and content of the speech was analyzed. Results: It was observed that all participants have a positive bond with their children, believing in the importance of maternal care as essential. However, the participants pointing out that the rules of the prison adversely affect the child's development and despite the fact that their babies were the only source of tenderness prefer that a relative took care of the baby. Future studies should include more participants and other informants. In conclusion it was found that system adaptation is required to fulfill early childhood needs of incarcerated mother's children and it is suggested that the bounding motherbaby could be promoted as a manner to re-socialize the incarcerated.
\end{abstract}

Keywords: prison, incarcerated mothers, early childhood

\title{
Introdução
}

No Brasil em 2014 existiam 37.380 mulheres encarceradas, fazendo com que a taxa de aprisionamento por 100.000 habitantes fosse de 18,5 , e mais especificamente entre a população feminina de 34,6 mulheres presas a cada 100.000 mulheres brasileiras (Departamento Penitenciário Nacional, DEPEN, 2015). O Brasil é o $5^{\circ}$ país com maior população prisional feminina, perdendo apenas para os Estados Unidos, China, Rússia e Tailândia. Há ainda uma tendência de aumento da população carcerária feminina, sendo que entre 2000 a 2014 aumentou 567\%, enquanto que a população carcerária masculina teve um incremento de $220 \%$ no mesmo período (DEPEN, 2015).

Havendo tantas mulheres presas no Brasil, é importante se perguntar quais são suas características, de modo a ir se delineando fatores de risco para o encarceramento e possibilidades de ressocialização. Ormeño (2013) revisou estudos sobre o perfil das mulheres encarceradas no âmbito nacional e internacional, percebendo semelhanças quanto as encarceradas brasileiras e norte- americanas (Bloom, 1995; Carvalho, 2007, Costa, 2003, Craig, 2009, Dalley, 2002; Greene, Haney, \& Hurtado, 2000). Nota-se que para além da condição de encarceramento, a mulher encarcerada comumente já vivenciou diversas situações adversas ao longo da vida: foi vítima de maus tratos na infância, inclusive vítimas de abuso sexual; teve familiares encarcerados seja um ou ambos os pais; evadiu da escola, tendo baixo grau de escolaridade; teve dificuldades financeiras; possuía mais de um filho; se constituía como chefes da família e envolvera-se com drogas, seja como usuária ou como traficante (Ormeño, 2013). Adicionalmente, o perfil da mulher encarcerada no Brasil, segundo o DEPEN (2015) envolve mulheres jovens (18 a 29 anos), sendo $67 \%$ negras, $57 \%$ solteiras, $21 \%$ estrangeiras, $35 \%$ cumprindo pena de 4 a 8 anos, 
$30 \%$ privada de liberdade em atividade laboral (destas $25 \%$ em atividades externas ao cárcere e $75 \%$ em atividades internas), $21 \%$ estão estudando e $5 \%$ apresenta agravos transmissíveis (sendo 46\% com HIV, 35\% sífilis, 4,6\% tuberculose, entre outros).

Em relação ao fato de que a maior parte das mulheres encarceradas encontram-se em faixa etária propícia a reprodução humana, torna-se necessário compreender o fenômeno da maternidade no cárcere. Contudo, são poucos os estudos sobre encarceradas no Brasil e menos ainda são as investigações sobre a relação mãe encarcerada e criança na primeira infância. $\mathrm{O}$ entendimento desta relação e do impacto do ambiente prisional no desenvolvimento infantil são importantes, para o desenvolvimento de estratégias preventivas e remediativas adequadas com relação a saúde da mãe e da criança e definição de leis que assegurem a assistência adequada as mães encarceradas e seus filhos.

A respeito da legislação, Ventura, Simas e Larouzé (2015) realizaram extensa pesquisa documental quanto a legislações federal e dos estados do Mato Grosso, Paraná, Rio Grande do Sul e São Paulo, tendo percebido 33 normas relativas à maternidade nas prisões. A Constituição Federal de 1988 permite às mulheres permanecerem com seus filhos durante o período de amamentação (Brasil, 1998). Ainda no âmbito da legislação federal, a Lei 7.210 de 11 de julho de 1984 institui que deve ser fornecido à mulher encarcerada e ao seu bebê acompanhamento médico, berçário, local próprio para a amamentação por no mínimo os 6 meses de idade da criança, creche para crianças maiores de 6 meses e menores de 7 anos e o benefício de regime aberto quando o filho for deficiente mental e físico.

Já a Resolução do Conselho Nacional de Política Criminal e Penitenciária institui a possibilidade mínima de permanência da criança com a mãe até ela completar 1 ano e 6 meses e, no máximo, até os 7 anos de idade. Na reforma processual penal de 2011, nos casos de prisão provisória, há ainda a possibilidade de prisão domiciliar quando a encarcerada estiver gestante a partir do 7o. mês de gravidez ou se for gestante de alto risco, se for imprescindível aos cuidados do filho menor de 6 anos ou para os cuidados de pessoa com deficiência. Há diferenças quanto a normas por estado, de modo que Ventura et al. (2015) recomendam que haja regulamentação específica que estabeleça um procedimento padrão quanto ao período de permanência e aos critérios quanto as condições mínimas para a boa convivência mãe e filho.

Assim, é permitido e possível que filhos permaneçam em ambiente prisional junto às suas mães durante toda a primeira infância, sendo importante que se atente para as características das mães encarceradas e os efeitos para as mães e crianças da maternidade na prisão. Quanto ao perfil das mulheres-mães encarceradas, um dos poucos estudos é o de Mello e Gauer (2011) o qual envolveu 30 mães encarceradas do Rio Grande do Sul e que notou que estas eram solteiras, tinham ao menos três filhos, estudaram menos do que 8 anos, estavam cumprindo pena por tráfico de drogas, tinham familiares e amigos em condição de encarceramento e já haviam consumido substâncias ilegais, ou seja, perfil semelhante às das encarceradas em geral. Adicionalmente, 31 mães encarceradas, 61,3\% afirmou fazer uso de nicotina, $48,4 \%$ de álcool e $29 \%$ de drogas ilícitas durante a gravidez, tendo iniciado o consumo destas substâncias antes do encarceramento.

Às condições de vida ruins das mães prévias à prisão, o fato de estas mães manterem o consumo de substâncias ao longo da gravidez, deve-se somar às condições prisionais que não são adequadas às próprias mulheres, o que certamente leva a pensar se seriam adequadas para as crianças. Apesar de ser um direito dos presidiários serem 
tratados com dignidade, cabe lembrar que segundo o DEPEN (2015) somente $40 \%$ das instituições prisionais femininas não estão em condição de superlotação, havendo 7\% de instituições em que para cada vaga disponível há três ou quatro mulheres encarceradas. Do total de unidades penitenciárias, somente $34 \%$ apresentavam cela ou dormitório adequados para a gestante, $32 \%$ tinham berçário ou centro de referência materno infantil e 5\% creche.

Apesar destas adversidades ao desenvolvimento infantil, Stella (2008) ao investigar a literária nacional e internacional, em relação à legislação de vários países, assim como no Brasil, destaca que é enfatizada a importância da construção do vínculo mãe-bebê enquanto um resultado benéfico da manutenção da criança junto da mãe encarcerada. Por um lado a mãe desenvolve maior capacidade para restruturar sua personalidade, e por outro lado, não priva a criança dos cuidados maternos considerados importantíssimos nos primeiros anos de vida. Conforme Campbell e Carlson (2012) estudos perceberam que as mulheres que puderam estar com seus bebês durante o período de encarceramento tem menores índices de reincidência em relação as que não tiveram esta possibilidade. Adicionalmente, Mello e Gauer (2011) apontaram que a permanência da criança no ambiente prisional propiciou à mãe diminuição dos efeitos negativos do encarceramento, uma vez que as presidiárias referem que o tempo passa mais rápido, por se manterem ocupadas com os filhos, há pequenas vantagens em relação as outras detentas sem filhos (por exemplos, ter uma cadeira à disposição, ser atendida com mais frequência por equipe de saúde e ter mais liberdade para circular no espaço prisional). Adicionalmente, Mello e Gauer (2011) apontaram que as mães referiram menor consumo de drogas com o nascimento dos filhos bem como relataram que estavam exercendo o papel de mãe pela primeira vez, pois muitas antes haviam tido filhos, mas não tiveram condições de criá-los principalmente devido ao abuso de substâncias. Ademais Giordani e Bueno (2001) e Lopes (2007) indicaram que as encarceradas possuem concepção da maternidade em que a mãe deve proteger e ter afeto para com a criança, tendo satisfação pessoal em ser mãe e sentimento de continuidade da espécie. O rompimento da relação mãe/filho é sinônimo de sofrimento, angustia e solidão para a díade.

Tendo em vista a importância da relação mãe-filho, alguns poucos autores brasileiros como Stella (2008) e Quintinho (2005) alertaram que as mães encarceradas seguem diretrizes e regulamentos prisionais com restrições e vigilância que difere da realidade de uma residência fora prisão e que essas condições acabariam "encarcerando" as crianças, privando-as de um ambiente social e familiar natural. Em perspectiva semelhante, Mello e Gauer (2011) apontaram que a estrutura física prisional pode ser favorecedor de más condições de saúde, uma vez que notaram que dos 26 filhos acompanhando a mãe no cárcere, $42 \%$ apresentava algum problema de saúde (10 crianças tinham asma e bronquite, uma sífilis e uma anemia).

Assim, em teoria, a convivência da criança pequena dentro dos presídios é defendida por considerarem-na saudável para o relacionamento mãe-criança, reforçando laços e contribuindo para o desenvolvimento do bebê e para a posterior reinserção social materna. Porém, seria a relação mãe-bebê em ambiente presidiário satisfatória e suficiente para um bom desenvolvimento infantil? Para a resposta desta questão certamente, deve-se considerar que em vários países a convivência do bebê/criança com a mãe encarcerada é valorizada e as próprias mães quererem desempenhar o papel de mãe, porém não há uma padronização internacional de tratamento destinado a mães com filhos, havendo diferentes 
manejos de tratamento pelo mundo, muitos dos quais ao invés de beneficiarem o desenvolvimento infantil e a maternidade, prejudicam-no.

Em virtude da carência de estudos na área do perfil das mães encarceradas e maternidade em contexto prisional, este estudo buscou conhecer e compreender sob a ótica da mãe encarcerada, quais são os aspectos relevantes no desenvolvimento da criança no ambiente prisional incluindo o nascimento e a permanência da criança.

\section{Método}

\section{Delineamento de pesquisa}

Optou-se pela metodologia qualitativa de caráter descritivo, com a finalidade de compreender as peculiaridades inerentes ao fenômeno maternidade no ambiente prisional. Cabe ressaltar conforme explicita Minayo (2012) que o verbo principal da análise qualitativa é compreender, o qual envolve a busca por colocar-se no lugar do outro, a qual sempre será incompleta seja porque o próprio pesquisador apresenta as suas contradições subjetivas quanto porque o próprio pesquisado não entende e não sabe mencionar todos os aspectos de sua vida, uma vez que inerentemente a vida é permeada de contradições. Independentemente dessa impossibilidade de um entendimento total, a pesquisa qualitativa é relevante, pois mesmo analisando comumente discursos de poucos sujeitos, estes expõem de alguma forma um discurso coletivo. Assim, se expressa Minayo (2012, p. 613): "Mas também é preciso saber que a experiência e a vivência de uma pessoa ocorrem no âmbito da história coletiva e são contextualizadas e envolvidas pela cultura do grupo em que ela se insere."

\section{Participantes}

Participaram do estudo três mães encarceradas que ingressaram no sistema prisional grávidas e realizaram o parto estando encarceradas, tendo sido condenadas por envolvimento com tráfico de drogas.

\section{Local do estudo}

A pesquisa foi realizada no Centro de Regime Semi- Aberto Feminino no Estado do Paraná. Na época do estudo encontravam-se encarceradas aproximadamente 184 mulheres, porém o exato número de encarceradas variavam diariamente devido à concessão de alvará de soltura e de progressão de regime. Dentre as encarceradas, conviviam cerca de cinco crianças menores de seis anos de idade. Algumas dessas crianças nasceram quando suas mães já estavam presas, enquanto outras a mãe usufruiu do direito legislativo de manter sob sua guarda filhos menores de 6 anos mesmo estando encarcerada.

No referido centro no regime fechado, as mães ficavam em celas junto a duas ou três detentas, sendo que os filhos permaneciam com a mãe até os 4 meses de idade no cárcere, após, a criança era destinada à creche instalada na própria instituição prisional. $\mathrm{Na}$ creche o cuidado das crianças é atribuído as próprias mães, sendo que é realizada uma escala em que se alterna o cuidado das crianças entre as mães. 
No que se refere ao Regime Semi- aberto, mães e crianças convivem em alojamentos conjunto de sete a oito treliches - durante o dia as mães saem do estabelecimento para trabalhar e as crianças frequentam um Centro Municipal de Educação Infantil (CMEI). Quando as crianças ainda não tem idade para frequentar a CMEIs, ou há carência de vagas, as mães ficam no estabelecimento para cuidar das crianças, perdendo o direto de trabalhar (Brasil, 1988).

No local do estudo havia uma sala de aula, a onde ocorreram as entrevistas. Estas foram realizadas de forma individual e sigilosa, em uma sala de aula escolhida pela direção do presídio e que continha várias cadeiras e carteiras, uma estante de fundo com livros e um quadro negro na parede.

\section{Instrumento}

Foi utilizado uma entrevista semi- estruturada baseada em Ormeño (2013) a qual divide-se em cinco partes: 1) informações sócio- demográficas e da constituição familiar, 2) histórico sobre a infância da encarcerada, 3) concepção do papel de mãe e da relação que possui com os filhos encarcerados, 4) percepções das mães sobre o desenvolvimento do filho(a) e a vivencia dele dentro do ambiente prisional e 5) expectativas quanto ao futuro. Apesar de já se ter um instrumento guia, cabe ressaltar que na pesquisa qualitativa "É preciso imergir na realidade empírica na busca de informações previstas ou não previstas no roteiro inicial" (Minayo, 2012, p.623).

\section{Recursos humanos}

As entrevistas foram realizadas por psicóloga a qual possuía vínculo trabalhista na instituição do estudo, o que facilitara o recebimento da anuência da direção do estabelecimento prisional e o acesso livre às detentas, sem que as entrevistas tivessem que ser acompanhadas de profissional de segurança.

\section{Recursos humanos}

Este estudo faz parte de um estudo maior, o qual foi aprovado por Comitê de Ética em Pesquisa com Seres Humanos sobre o CAAE 0016.0.135.000-09, tendo-se respeitado a resolução 466/2012 do Ministério da Saúde. Assim, somente participaram as mulheres que assinaram Termo de Consentimento Livre Esclarecido - TCLE, tendo-se explicitado que ao longo das entrevistas poderiam surgir emoções negativas diante de algum assunto abordado sobre suas vidas, mas que poderiam interromper a participação no momento que julgassem necessário, sem qualquer implicação negativa a elas, e a entrevistadora por ser psicóloga estava preparada para acolher as angústias que por ventura surgissem.

\section{Procedimentos de coleta e análise de dados}

A entrevistadora dirigiu-se até a galeria (local onde as participantes dormem) e convidou-as a participarem, aquelas que aceitaram, após leitura do TCLE, assinaram-no. Após o consentimento por escrito, fez-se entrevistas com cada participante individualmente em dois momentos distintos, a fim de se evitar cansaço, somando um total 
de aproximadamente duas horas. Devido à questões de segurança, no local do estudo proibesse a entrada de aparelho celular, gravador ou sistema de informação portátil, sendo que as informações coletadas foram anotadas manualmente durante a entrevista e após a mesma, utilizando-se das recordações da entrevistadora.

Após a coleta de dados, fez-se a organização dos mesmos de acordo com as categorias: 1) Perfil sócio- demográfico e características gerais das mães encarceradas; 2) Aspectos da infância das encarceradas e quais foram os modelos que tiveram do papel de mãe; 3) Percepção do cuidar do filho na prisão e dos apoios externos à prisão para o cuidar e 4) Planos para o futuro. Tendo-se feito tal organização, partiu-se para o esforço de interpretar as informações à luz da literatura nacional e internacional e das próprias vivências dos pesquisadores, pois conforme apresenta Minayo (2012), a pesquisa qualitativa não deve encerrar-se em uma mera descrição, deve ocorrer uma interpretação capaz de tornar compreensível o discurso coletivo que aqueles discursos individuais apresentam.

\section{Resultados e discussão}

\section{Perfil sócio- demográfico e características gerais das mães encarceradas:}

Todas as entrevistadas eram jovens, P1 tinha 29 anos, P2 20 anos e P3 21 anos, de modo que encontravam-se na faixa etária a qual outros estudos (DEPEN, 2015; Ormeño, 2013) apontaram ser mais recorrente a situação de encarceramento. As entrevistadas também possuíam baixa escolaridade, baixo status sócio- econômico e foram presas por envolvimento com tráfico de drogas, o que novamente foi semelhante à literatura que traçou o perfil das encarceradas (DEPEN, 2015, Ormeño, 2013, Mello \& Gauer, 2011), P1 e P2 estudaram até o $4^{\circ}$ ano e P3 até o 5o. ano do Ensino Fundamental.

A experiência da maternidade já tinha ocorrido anteriormente à prisão para duas delas. P1 e P2 tinham mais de um filho, sendo que P1 apresentava quatro filhos e P2 dois filhos, o que foi semelhante ao estudo de Mello e Gauer (2011). Das três entrevistadas, duas delas já estavam grávidas antes de serem presas. P1 foi presa quando estava grávida de quatro meses e P2 quando estava no quinto mês de gestação, nascendo os bebês no cárcere, já P3 engravidou durante o cumprimento da pena, tendo sua filha nascido prematura.

Das três mulheres, P1 era casada pela segunda vez, P2 estava divorciada, pois após sua prisão, o marido a abandonara com a explicação de que nem ele e tampouco outros integrantes da família envolveram-se com atos ilícitos e P3 estava casada pela primeira vez.

\section{Aspectos da infância das encarceradas e quais foram os modelos que tiveram do papel de mãe;}

A infância de P1 foi marcada pela instabilidade econômica familiar sendo que, por isso, várias vezes teve que morar com outras pessoas (primos, tios e amigos da família). Começou a trabalhar de cuidadora de crianças aos 10 anos e relata que essa oportunidade de "trabalho" (sic) foi "a melhor coisa que fez na vida" (sic). Relatou que na sua infância 
foi criada pela avó até os 14 anos, após esta idade foi morar com sua mãe que a expulsou de casa aos 15 anos por conta dos assédios sexuais cometidos pelo padrasto. Já P2 também referiu uma infância difícil em relação a questões socioeconômicas e afetivas e exemplos na família de envolvimento em atividades criminosas, sendo que a mãe de P2. teve envolvimento com o tráfico de drogas e também estava presa no Regime Fechado. P3. relatou que também teve uma infância conturbada, seu pai era dependente de drogas, disse que nunca recebeu afetividade materna e que em várias ocasiões foi transferida aos cuidados de outros familiares, aos 12 anos retornou a família de origem e quando ela tinha 14 anos, sua mãe abandonou a família, tendo dois irmãos menores ficado aos cuidados dela.

Assim, marcadamente nota-se nos três casos uma infância marcada por adversidades sócioeconômicas, as quais certamente influenciaram na baixa adesão à escola, e por conseguinte às poucas oportunidades de ocupação antes de serem encarceradas. Adicionalmente, a falta de afeto por parte dos familiares ao longo da infância, a instabilidade das figuras maternas e paternas, dificultaram o desenvolvimento de um apego seguro, da sensação de pertencimento social e o desenvolvimento por meio de modelos do que seriam habilidades maternas. Novamente, estes dados vão ao encontro da literatura atual (Ormeño, 2013).

Apesar de não terem tido exemplos adequados do papel de mãe com suas próprias mães, todas as participantes indicaram ser muito importante o sentimento afetuoso (amor e carinho) contínuo como base ideal para uma criança, o que já fora apontado pelas mães entrevistadas na pesquisa de Mello e Gauer (2011).

\section{Percepção do cuidar do filho na prisão e dos apoios externos à prisão para o cuidar}

As participantes disseram que durante a gestação na prisão, receberam os cuidados necessários de pré-natal e o recém- nascido foi acompanhado pelo pediatra, o que certamente é um aspecto positivo que pode ter sido propiciado pela condição do encarceramento uma vez que houve organização institucional para criar oportunidades de supervisão da gravidez e dos primeiros meses de vida por profissional de saúde, o que talvez se as participantes estivessem libertas, por dificuldades financeiras e de conflitos familiares, não tivesse ocorrido.

Todas as participantes referiram sentimento de tristeza diante de algumas imposições e características da instituição quanto aos cuidados das crianças no regime prisional, o que se revela similar as preocupações já apontadas por Stella (2008) e Quintino (2005). Cabe mencionar que na referida instituição havia poucas opções alimentares; arroz, feijão, macarrão, carne, frango, quatro tipo de verduras, três tipos de frutas, pão, margarina, cevada e leite. Havia, também, restrição de estímulos ambientais, como a falta de contato com animais, plantas e objetos do cotidiano de outras crianças, como telefone e brinquedos. Ademais, havia limitação do espaço físico que não oferecia amplo suporte para acomodar objetos e vestimenta das crianças e para as crianças brincarem.

P1 relatou que sentiu-se triste quando a criança completou 4 meses de idade, pois obrigatoriamente era necessário que o bebê fosse para o berçário interno da prisão, onde durante o dia as mães revezavam os cuidados com as crianças e durante a noite ficavam 
sobre o cuidado das guardas. P2. comentou que as mudanças no dia a dia na progressão de Regime fechado para o Semi- Aberto gerou dificuldades no cuidado da filha, afirmando que "o semi aberto é diferente" uma vez que a interação entre as presas ocorre mais ativamente, gerando conversas, risadas, barulhos que nem ela e nem o bebê estavam acostumadas. P2 diz que a filha passou a recusar a alimentação e parece ter medo das pessoas, desde que ambas foram transferidas para o regime semiaberto. Assim P2. referia que não "aguentava" ver a filha nesta situação, se sentindo mal, angustiada, triste e chorando muito. Gostaria de voltar para o regime fechado, porém, sabe que o semiaberto vai oferecer mais condições para o desenvolvimento da filha: "Aqui posso dormir com minha filha do meu lado, coisa que nem sabia como era...".

P3 relatou que era muito difícil cuidar da filha na cadeia, pois o espaço físico era restrito, o que deixava a criança agitada; as alimentos eram restritas em variedade, não tinha lugar adequado para o banho, sendo que o espaço utilizado era coletivo com as demais internas; as outras encarceradas não respeitavam as crianças, fazem barulho, o que tornava o ambiente pesado. Ela acreditava que o ambiente prisional "nunca" seria um lugar para criar um filho, porque além do espaço físico restrito, restringe-se o contato da criança com os outros membros da família. P3 assim relatou: "Eu pago a cadeia 2 vezes, a minha e a da minha filha...choro muito por manter ela aqui dentro!"

Diante destes relatos, nota-se que apesar de a literatura científica (Campbell \& Carlson, 2012; Melo \& Gauer, 2011; Stella, 2008) apresentar vantagens da permanência da criança junto à sua mãe no ambiente prisional para a ressocialização da mesma e a diminuição dos efeitos negativos do encarceramento, no presente estudo ficou evidente que as mães indicam que as condições oferecidas pela instituição são deletérias para o desenvolvimento infantil. Estes dados apontados são análogos aos apontados por Giordani e Bueno (2001) e Ormeño (2013) em que mães encarceradas apresentaram capacidades de exercer sua maternidade, em relação a questão afetiva, embora as condições das instituições prisionais não sejam as mais adequadas. A partir dos relatos, verificou-se a necessidade de que haja espaço para as crianças brincarem, terem suas roupas guardadas e que exista maior variabilidade de alimentos disponíveis. É importante também que a criança possa ter oportunidades de participar de atividades junto a família extensa e não apenas com a mãe e que a transferência do presídio para os cuidados de outros familiares ocorra de maneira planejada, minimizando o sofrimento de mãe e criança. Tal planejamento deve compreender o afastamento gradual do local de encarceramento, a recepção da criança por uma pessoa confiável, afetuosa e que possa prover os cuidados de alimentação, higiene e educação para a criança e a oportunização de momentos de interação mãe e criança de modo a manter o vínculo entre ambas.

Tendo em vista estas dificuldades para o desenvolvimento infantil, as encarceradas ao notarem o sofrimento do filho, ainda que queiram estar perto deles e acompanhá-los, passam a se sentir preocupadas, culpadas e desejosas de que este tenha a oportunidade de serem assistidos longe da prisão, de modo que, quando há assistência de pessoas eternas à prisão, não chegam a usufruir do direito de estarem junto aos filhos até no mínimo 1 ano e seis meses e até no máximo completarem 7 anos (Ventura et al., 2015).

P1 quando a filha fez 2 anos decidiu por pedir que a avó materna que cuidasse dela fora do presídio, dizendo que gostaria de cuidar dos filhos, porém, o mais importante é pensar no que é melhor para a criança: "Eu deixei minha filha para minha mãe cuidar, porque sei que é melhor para ela! Neste lugar, acho que até os 2 anos a mãe tem que 
cuidar dos filhos, uma psicóloga me explicou isso!... só deixei ela lá porque minha mãe passou confiança... tinha a cama onde ela ia dormir, o lugar para guardar as roupinhas... estou sofrendo, sinto falta dela!...mas não posso ser egoísta e pensar só em mim!... eu que sou obrigada a passar por isso!...eu que fiz errado, não ela!”. Esta participante ainda afirma que enviou a filha aos familiares porque percebeu que a prisão estava limitando o desenvolvimento da criança, relatou que a criança tinha medo de animais de estimação, não conhecia vários alimentos e havia muitos objetos do cotidiano que desconhecia. $\mathrm{A}$ participante receava se mantivesse a criança com ela na prisão após ela completar dois anos de idade, quando adulta, a filha pudesse lembrar do que viveu durante a prisão, e temia que ela interiorizasse a prisão como um ambiente "normal".

P2 afirmou que pensou em enviar a filha para o pai, pois o maior de seus sofrimentos, é ver sua filha tendo pouco acesso a variedade de objetos e ser exposta a outras presidiárias que nem sempre agem de modo respeitoso com a criança: "...outro dia, outra criança tava com doce e minha menina viu, a outra criança não deu pra ela, eu não pude fazer nada, só abracei ela e chorei...no regime fechado as outras mães batiam nela, também não pude fazer nada!...não aguento mais ver isso...eu não bato na minha filha....ela já sofre demais...".

P3. também disse que pensou em pedir que a criança fosse cuidada pela avó paterna, porque sabe que com a sogra a criança receberá melhor assistência. A participante relata que no dia anterior à entrevista estava preocupada com a filha que chorava demasiadamente, solicitou ajuda, porém, foi negado o atendimento. P3. sentiu-se humilhada pelo tratamento recebido, o que provocou sua ira e sentiu vontade de agredir a guarda. Não o fez, pois isto aumentaria o período de condenação. Explicou que esse pensamento ocorreu porque a situação estava relacionada diretamente a sua filha, caso o contrário, "jamais pensaria dessa forma". O motivo dela ainda não ter deixado a filha com a sogra é por causa da amamentação, uma vez que a menina tinha menos de 6 meses de idade e, principalmente, pelo amor que sente pela filha e alegria de tê-la por perto.

Com relação aos apoios externos à prisão, $\mathrm{P} 1$ e P3 recebiam ajuda, especialmente das sogras, enquanto que P2 era negligenciada. P1 havia deixado seus dois filhos do primeiro casamento com o pai biológico, e disse receber apoio afetivo/emocional da família do atual marido após o encarceramento, o que para ela foi motivo de surpresa. P3 também se emocionou ao falar do pai de sua filha e de sua sogra, pois surpreendeu-se com os cuidados recebidos após a prisão, pois disse que "nunca recebi tanto amor e carinho na vida, considero minha sogra como uma mãe de verdade" e eles forneciam todo o apoio financeiro para o sustento da filha. É interessante notar que o bebê ainda não conhecia o pai nem a família, mas na semana seguinte à entrevista $\mathrm{P} 3$ teria o direito de ir visitá-los com o bebê. Já P2. não tinha contato com os familiares e tampouco recebia auxilio deles o que se distinguia da situação das outras presas, as quais comumente recebiam produtos de higiene, vestuários e alimentos permitidos dentro do sistema penitenciário. P3 relatou que realizava os cuidados de higienização e vestimenta da filha com ajuda de outras presas e das agentes penitenciárias, uma vez que não havia amparo do governo com relação ao fornecimento dos subsídios mínimos para o cuidado.

Estes relatos destacam primeiramente o fato de que o gerar um filho pode em alguns casos favorecer a sensação de pertencimento social, pois as famílias aproximaramse mais da encarcerada, contudo é interessante notar que a aproximação nos casos relatados deu-se pela família do companheiro e não da própria detenta e mais fortemente 
ligada à figura feminina no papel da sogra. Assim, fica evidente como a condição prévia ao encarceramento destas mães envolvia o grande afastamento de suas famílias de origem, o que pode inclusive ter favorecido a realização do ato infracional, uma vez que estavam desprovidas de apoio emocional e financeiro. Adicionalmente, estes relatos denotam a situação do papel que tradicionalmente vem sendo delegado pela sociedade à mulher, a qual acaba por ser o ente familiar que mantém a família unida e que no presente estudo exerciam a função de amparar filhos (companheiros das detentas), noras e, por conseguinte, os netos.

Em relação à ausência de apoio que $\mathrm{P} 2$ recebia, ficou nítida a lógica machista do marido e dos familiares dele para justificar tal negligência, a qual infelizmente não é incomum na sociedade brasileira. Primeiramente, a responsabilidade de cuidar foi fornecida inteiramente à mãe, e esta apressadamente foi classificada como indigna de atenção, uma vez que cometera o ato infracional. Portanto, o ato infracional cometido pela detenta foi analisado pelo ex-marido e familiares dele de maneira descontextualizada das condições sociais em que viviam, das relações interpessoais que haviam sido estabelecidas entre esposa e marido e entre esposa e outros familiares e, até mesmo, da história de vida da encarcerada a qual foi marcada por adversidades. É ainda possível hipotetizar que o fato de o bebê gerado ter sido uma mulher tenha ainda pesado para o distanciamento por parte do marido e seus familiares, visto em alguns casos na sociedade brasileira ainda se querer um "filho homem".

\section{Planos para o futuro}

Todas as participantes tinham planos para o futuro, nos quais vislumbravam ter uma ocupação a qual permitisse sustentar o filho. P1 afirmou que "quero continuar trabalhando na mesma empresa que atuo hoje na prisão, penso em alugar e mobiliar uma casa para poder buscar minha filha e construir uma nova família.", já P2 disse "quero arrumar um trabalho para dar condições boas para meus filhos" e P3 afirmou que "pretendo deixar minha filha numa creche para poder trabalhar". Esses relatos indicam a importância de que na prisão haja condições para que as mulheres desenvolvam suas habilidades ocupacionais, de modo que no futuro possam competir por empregos rentáveis, evitando a reincidência. Adicionalmente, indica-se a importância de haver ocupações externas à prisão enquanto cumprem pena, de modo que podem vislumbrar com mais consistência possibilidades de trabalho, como fez P1. E, como bem lembrou P3 certamente para que consigam trabalho após a soltura, deve haver programas sociais que auxiliem estas mulheres a cuidar dos filhos, visto que apresentam pouco ou nenhuma rede social (familiares da família de origem distantes e no caso de P2 ausência total de apoio de qualquer familiar).

Então, os projetos futuros de todas envolviam conseguirem um emprego que permita o sustento dos filhos e formação de uma família marcada pelo afeto, descartando a possibilidade de se envolver novamente com atos ilícitos. Não entanto, precisa ser aplicados programas que as assistam na reinserção social, considerando o baixo nível escolar, o currículo carente de experiências ocupacionais formais e o preconceito da sociedade por serem ex-detentas.

Ainda em relação ao futuro, notou-se que há sensação de culpa e insegurança em relação a como os filhos irão percebê-las diante do fato de terem sido encarcerdas. P1 
desejava que sua filha não esquecesse dela e que a criança entendesse futuramente que a sua decisão de deixá-la com a avó paterna foi baseada no bem estar da criança. P2 disse pretender dedicar-se aos filhos no futuro, pois acreditava que sua prisão fez seus filhos sofrerem e pretendia compensar "todo esse sofrimento" de alguma forma, gostaria de fazer a eles "tudo que nunca tive na vida (amor de mãe, carinho e cuidados)". Já P3 enfatizou que terá que esforçar-se para ser uma mãe dedicada, amorosa no que difere da sua mãe.

Certamente, a tarefa de cuidar de crianças não é fácil. Assim há extensa literatura sobre quais seriam as habilidades e estilos parentais desejáveis e a necessidade de que sejam aplicados treinamentos de pais para maior garantia de que os pais consigam bem cuidar de seus filhos (por exemplo, ver Bolsoni-Silva \& Borelli, 2012; Macarini, Martins, Minetto, \& Vieira, 2010). Supõe-se que devido a história de vida difícil a qual estas mulheres foram submetidas e a pequena rede de apoio que apresentam, ainda que desejem sempre terem um bom vínculo afetivo com seus filhos, seria importante que hajam programas que promovam o desenvolvimento das habilidades maternas das mesmas e o amparo dos filhos para que compreendam a situação de encarceramento de suas mães. Situações de vulnerabilidade social em população de encarcerados são apontadas tanto em estudos nacionais como internacionais, mostrando a necessidade de suporte para esta população e para seus filhos, visando romper a intergeracionalidade carcerária (Canazaro \& Argimon, 2010; Dalley, 2002, Quintinho, 2005).

\section{Considerações finais}

O presente estudo teve como objetivo compreender sob a ótica da mãe encarcerada quais são os aspectos relevantes no desenvolvimento da criança no ambiente prisional, tendo percebido que apesar de para as mães investigadas a convivência com o bebê ser fonte de afeto e de motivação para que se ressocializem o mais rapidamente quanto possível, estas apontaram que para os filhos o ambiente prisonal não oportuniza $o$ adequado desenvolvimento de modo que preferem que sejam cuidados por familiares fora do ambiente prisional.

É importante, contudo, salientar que se houvesse adequação do ambiente prisional para o recebimento das crianças, a permanência destas com suas mães promoveria tanto melhoras na saúde mental das encarceradas, diminuiria o risco de reincidência e promoveria um adequado desenvolvimento infantil. Dentre as adequações necessárias, a partir dos relatos, julga-se necessário espaços exclusivos para mãe e criança, fornecimento das características básicas para o cuidar da criança (fraldas, roupas, produtos de higiene, alimentação diversa, brinquedos, espaço físico arejado e com plantas, facilidade de acesso a outros familiares), atividades de reflexão e empatia junto a outras detentas para que compreendam as particularidades da primeira infância de modo a bem tratarem as crianças das encarceradas e programas de assistência social que visem o resgate de vínculos entre estas mulheres e suas famílias de origem, bem como a manutenção do vínculo que possuem com seus companheiros e a família destes.

Dentre as limitações deste estudo têm-se: pequeno número de mulheres entrevistadas e que estavam inseridas na mesma instituição, entrevistas apenas com as encarceradas, não tendo sido investigado a percepção dos familiares, das crianças e dos funcionários da instituição. Recomenda-se a realização de mais estudos, envolvendo maior número de participantes, cumprindo pena em diferentes estados e com outros informantes. 
Apesar destas limitações, este é um dos poucos estudos no Brasil sobre o tema e aponta para a necessidade de que sejam feitas mais investigações e atuações práticas e políticas de modo que o Direito das mulheres encarceradas e de seus filhos de conviverem sejam respeitados efetivamente, isto é, não basta incluir as crianças junto das mães sem dar condições para que haja um adequado desenvolvimento infantil no contexto prisional.

\section{Agradecimentos}

Agradece-se a Jaqueline Moreira da Silva por ter participado da coleta de dados do presente artigo.

\section{Referências}

Bloom, B. (1995). Imprisioned mothers. In: Johnston D,., editor. Children of incarcerated parents. New York: Lexington Books. p. 21-30.

Brasil (1988). Constituição da República Federativa do Brasil. Recuperado de http://www.planalto.gov.br/ccivil_03/Constituicao/Constituicao.htm

Bolsoni-Silva, A. T., \& Borelli, L. M. (2012). Treinamento de habilidades sociais educativas parentais: comparação de procedimentos a partir do tempo de intervenção. Estudos e Pesquisas em Psicologia, 12 (1), 36-58.

Canazaro, D., \& Argimon I. (2010).Características, sintomas depressivos e fatores associados em mulheres encarceradas no Estado do Rio Grande do Sul, Brasil. Cadernos de Saúde Pública, 26(7): 1323-1333.

Campbell, J., \& Carlson, J. (2012). Correctional administrators'perceptions of prison nurseries. Criminal Justice and Behavior, 39(8), 1063-1074.

Carvalho, F. O. (2007). Desenvolvimento, mulheres e criminalidade: Uma análise dos relatos das presidiárias detidas por envolvimento com tráfico de drogas na cadeia pública de Montes Claros [Dissertação de Mestrado]. Montes Claros: Programa de Pós-Graduação em Desenvolvimento Social da Universidade Estadual de Montes Claros.

Costa, I. B. (2003). Mães encarceradas: Onde estão seus filhos? Um estudo de caso de uma unidade prisional de Recife-Pernanbuco [Dissertação de Mestrado]. Viçosa: Programa de Pós-Graduação em Economia Doméstica daUniversidade Federal de Viçosa.

Craig, S. (2009). A historical review of mother and child programs for incarcerated women. The Prison Journal, 89, 35-53.

Dalley, L. P. (2002). Policy Implications Relating to Intimate Mothers and their Children: Will the Pasta Be Prologue? The Prison Journal,82, 234-268.

Departamento Penitenciário Nacional (DEPEN, 2015). Levantamento Nacional de Informações Penitenciárias. Acessado em 26 de fev. Disponível em 
http://www.cnj.jus.br/files/conteudo/arquivo/2015/11/080f04f01d5b0efebfbcf06d 050dca34.pdf

Giordani, A. T., Bueno,S. M. V. (2001). A maternidade para mulheres detentas e a transmissão de DST/AIDS. Jornal Brasileiro de doenças sexualmente transmissíveis, 13(6): $12-24$.

Greene, S., Haney, C., Hurtado, A. (2000). Cycles of pain: risk factors in the lives of incarcerated mothers and their children.The Prison Journal, 80,3-23.

Lopes, R. (2007). Prisioneiras de uma mesma história: 0 amor materno atrás das grades. Imaginário USP, 13(14): 439-459.

Macarini, S. M., Martins, G. D. F., Minetto, M. F. J., \& Vieira, M. L. (2010). Práticas parentais: uma revisão de literatura brasileira. Arquivos Brasileiros de Psicologia, 62(1), 119134.

Mello, D. C., \& Gauer, G. (2011). Vivências da maternidade em uma prisão feminina do Estado do Rio Grande do Sul. Saúde e transformação social, 1(3), 113-121.

Minayo, M. C. de S. (2012). Análise qualitativa: teoria, passos e fidedignidade. Ciência e Saúde Coletiva, 17(3), 621-626.

Ormeño, G. I. R. (2013). Histórico familiar de mulheres encarceradas: fatores de risco e proteção para os filhos [Tese de Doutorado]. São Carlos: Programa de Pós graduação em Psicologia da Universidade Federal de São Carlos.

Quintinho, S. A. (2005). Creche na prisão feminina do Paraná - Humanização da pena ou intensificação do controle social do Estado? [Dissertação de Mestrado]. Paraná: Programa de Pós graduação em Sociologia da Universidade Federal do Paraná.

Stella, C. (2008). Creches em presídios: limites e possibilidades. [Relatório de pesquisa]. São Paulo: Universidade Presbiteriana Mackenzie.

Ventura, M., Simas, L., Larouzé, B. (2015). Maternidade atrás das grades: em busca da cidadania e da saúde. Um estudo sobre a legislação brasileira. Cadernos de Saúde Pública, 31(3), 607-619.

Recebido / Received: 18/04/2015

Aprovado / Approved: 29/11/2015 